\title{
Placement replacement: A conceptual framework for designing simulated clinical placement in occupational therapy
}

\author{
Author details \\ ${ }^{1}$ Dr Eli Mang Yee CHU PhD, GCHE, BSc (OT) \\ Formerly, Lecturer, School of Allied Health \\ Australian Catholic University \\ Locked Bag 4115, Fitzroy MDC, Fitzroy Victoria 3065, Australia \\ Associate Professor Loretta SHEPPARD DClinSci, MOT, GCHE, BAppScOT \\ Associate Professor in Occupational Therapy, School of Allied Health \\ Australian Catholic University \\ Locked Bag 4115, Fitzroy MDC, Fitzroy Victoria 3065, Australia \\ Dr Stephen GUINEA PhD, GradDipVocTrainDevelop, BN \\ Coordinator of Health Simulation, Faculty of Health Sciences \\ Australian Catholic University \\ Locked Bag 4115, Fitzroy MDC, Fitzroy Victoria 3065, Australia \\ Professor Christine IMMS BAppSc(OT); MSc(RS), PhD \\ Head of School, School of Allied Health \\ Australian Catholic University \\ Locked Bag 4115, Fitzroy MDC, Fitzroy Victoria 3065, Australia \\ Correspondence \\ Dr Stephen GUINEA \\ Faculty of Health Sciences \\ Australian Catholic University \\ Locked Bag 4115, Fitzroy MDC, Fitzroy Victoria 3065, Australia \\ Email: stephen.guinea@acu.edu.au \\ Tel: +61 399533857 \\ Author contributions \\ SCP conceptualisation: E.C., S.G. and L.S. \\ Conceptual framework design: E.C., L.S., S.G. and C.I.
}

${ }^{1}$ Currently (as of 19 June 2017), Senior Lecturer, Department of Occupational

Therapy, School of Primary and Allied Health Care, Monash University, Wellington

Road, Clayton Victoria 3800, Australia

This is the author manuscript accepted for publication and has undergone full peer review but has not been through the copyediting, typesetting, pagination and proofreading process, which may lead to differences between this version and the Version of Record. Please cite this article as doi: $10.1111 /$ nhs.12551

This article is protected by copyright. All rights reserved. 
Manuscript writing and revisions for important intellectual content: E.C., S.G., L.S. and C.I.

\section{Running title}

Placement replacement: The CF-SCP

This article is protected by copyright. All rights reserved. 
Disclosure: The authors declare no financial support or relationships that may pose conflict of interest.

\section{Acknowledgements}

We would like to acknowledge the members of the Occupational Rehabilitation Specialist Interest Group of Occupational Therapy Australia Ltd, (Victoria Division) who participated in the consultation process.

\section{Word count}

5485

\section{Abstract}

Simulation is increasingly used to supplement clinical placement in pre-registration health professional programs. However, there are no conceptual frameworks to guide the design of these learning experiences when replacing a clinical placement. In this paper the Conceptual Framework for Simulated Clinical Placements (CF-SCP) is presented. Evolving from an iterative process of synthesising learning and simulation theory, findings from the empirical literature, and the perspectives and ideas from experts in occupational therapy practice, education and simulation-based learning, the CF-SCP aligns principles and processes of workplace and simulation learning. The application of the CF-SCP is described in the context of a one-week full-time SCP. The CF-SCP provides a structure for organising, understanding and applying the principles and processes to design a simulated placement to be a 'placement replacement' experience. Articulating a conceptual framework for the design of simulated placement experiences to replace actual clinical placement hours in the allied health sector is important if these experiences are to be tested for validity, efficacy and transferability to a range of occupational therapy practice areas and other health disciplines.

Key Words occupational therapy, professional practice education, simulation, simulated clinical placement, Conceptual Framework for Simulated Clinical Placements 


\section{Background}

Over the past 10 years there has been significant growth in the number of occupational therapy programs in Australia, increasing pressure on providing professional practice placements for students (Occupational Therapy Council, 2012, 2015). Other health disciplines also report this trend nationally and internationally (Rodger et al., 2008; Smith, Corso \& Cobb, 2010; Stratton et al., 2015). For professional degree programs such as occupational therapy, theoretical knowledge from formal education must be supported by exposure to the practice environment for learning to be maximised (Billett, 2011; Billett \& Henderson, 2011; Hager, 2011; Oppermann \& Specht, 2006).

\section{Simulation in nursing and allied health}

Simulation as an educational method is used by healthcare disciplines because of the ability to "replace or amplify real experiences with guided experiences, often immersive in nature, that evoke or replicate substantial aspects of the real world in a fully interactive fashion" (Gaba, 2004, p. i2). In occupational therapy, practice comprises a complex nexus of clinical skills, patient safety, communication, and engagement with the inter-professional team. Simulation offers practice in these skills in a formative and supportive environment providing a valid placement experience that can be provided to high numbers of students and better prepare them for their traditional clinical placements (Rodger, Bennett, Fitzgerald \& Neads, 2010).

This article is protected by copyright. All rights reserved. 
Simulation is incorporated in pre-registration allied health professional curricula using simulated patients, role-play, written case scenarios and video-based simulations (Hill, Davidson \& Theodoros, 2013; Shea, 2015; Shoemaker et al., 2011). Emerging evidence supports the use of simulation as a valid, partial substitution for traditional placement in undergraduate physiotherapy and nursing education with student performances found to be comparable between the two (Watson et al, 2012; Hayden, Smiley, Alexander \& Kardong-Edgren, 2014). With growing evidence and increased acceptance from the healthcare education community, the possibility of using simulation to replace a complete clinical placement has become more plausible.

Developing simulation experiences to replace clinical placement does, however, require a theoretical basis. Theoretical perspectives that align simulation design and workplace learning have not been overtly considered in previous studies investigating the efficacy of simulation to replace placement. In addition, the use of a structured, cohesive simulation design to replicate complex, authentic and coherent practice has not yet been developed or tested. Lavoie and colleagues (2018) found that 79 of 182 articles included in their systematic review of simulation efficacy did not explicitly refer to theory. The remaining studies most frequently cited the National League for Nursing (NLN) Jeffries Simulation Framework, Kolb's theory of experiential learning, and Bandura's social cognitive theory and concept of selfefficacy. No papers reported a conceptual framework for designing simulated clinical placement that meets occupational therapy professional accreditation standards (Lavoie et al., 2018). Thus, the purpose of this paper is to present a theoretically- 
driven conceptual framework, the CF-SCP, for designing simulated clinical placements in occupational therapy. Application of the framework is then explicated through its use in designing a one-week simulated clinical practice experience in occupational therapy.

\section{Simulation in Occupational Therapy}

Using simulation to replace some professional practice hours is gaining acceptance by occupational therapy programs in Australia. Rodger et al., (2010) and later Imms et al. (2014) identified that eight out of 16 Australian universities used simulation-based activities as replacement for clinical placement hours in occupational therapy programs. However, these activities constituted far fewer than the $20 \%$ of clinical placement hours allowed by the professional accreditation body, largely due to limited evidence of the effectiveness of simulation to replace clinical hours and poor articulation of theoretical concepts. According to Shea (2015), high quality, high-fidelity simulation in occupational therapy consists of realistic equipment, a realistic environment, and the use of standardised patients to replicate a real situation. This author pointed to the need for stronger theory-based research to explore the effectiveness of simulation in occupational therapy. Hence, a theory-based conceptual framework is needed to advance such research in occupational therapy education.

\section{Theories, Models and Frameworks of Healthcare Simulation}

This article is protected by copyright. All rights reserved. 
The healthcare simulation literature reports a number of theories, models and frameworks. The most commonly cited is NLN Jeffries Simulation Theory (Jeffries, Rodgers \& Adamson, 2016). This theory was initially conceptualised as a framework based on a synthesis of core concepts drawn from literature and expert opinion (Rizzolo, Durham, Ravert \& Jeffries, 2016). The framework has evolved in to a theory, comprising seven concepts: (i) context, which refers to the place and purpose of the simulation; (ii) background, which includes the goals, specific expectations, position of simulation in the curriculum, theoretical perspectives and resource considerations; (iii) design, which is based on specific learning objectives that guide the selection of activities; takes into consideration the physical and conceptual fidelity; identifies the participants' and observers' roles; and sequences the progression of activities to include briefing and debriefing strategies; (iv) the simulation experience, which must be interactive, collaborative and learner-centred; ( $v$ and vi) the dynamic interaction between the facilitator and participant, which also impacts the simulation experience and is particularly affected by the facilitator's ability to adjust educational strategies in response to the learning needs of the participants; and (vii) participant, patient and system outcomes. The NLN Jeffries Simulation Theory describes factors to be considered in designing a simulated learning experience with an emphasis on the dynamic interaction between facilitator and participant. This theory does not, however, consider theoretical perspectives of workplace learning required for an authentic 'placement replacement' experience. 
The Simulation Model for Improving Learner and Health Outcomes (SMILHO), developed by Aebersold and Titler (2014), consists of three concepts related to the use of simulation as a teaching technique: (i) learner event; (ii) activity engagement; and (iii) debriefing. The SMILHO focuses on the design and implementation of the learner event with clear learning objectives around a specific content area. The learning event concept is based on Kolb's (1984) theory of experiential learning, Ericsson's $(2004,2008)$ perspective of deliberate practice and Aldrich's (2009) work on simulation and serious games. The design of the learning event aligns learning outcomes with the use of specific technology selected to trigger an event which elicits learner behaviour (Aebersold and Titler, 2014). Activity engagement is also an essential concept in SMILHO and the selection of appropriate technology is key to ensuring the immersion of the learner (Aldrich, 2009). The third essential concept, debriefing, conceptualises the simulation as reflective practice. Like the NLN Jeffries Simulation Theory, the interplay between the learning event, activity engagement and debriefing influences the outcomes of simulation. Both Aebersold and Titler (2014) and Jeffries et al. (2016) acknowledge the emergent nature of evidence about the impact of simulation on health outcomes and note the need for more research in this area.

In a third example, Chiniara et al.'s (2013) conceptual framework for the design of a simulation experience for healthcare comprises four levels. Level 1 is the instructional medium relating to the principle mode of delivery, for example, textbook learning, lectures, or simulation. Level 2 focuses on the selection of the simulation 
modality and how this affects the learning experience. Level 3 is the instructional method or the desired techniques for learning and teaching, either self-directed or instructor-directed. Level 4 is presentation, the characteristic which defines the implementation of the simulation and includes feedback, fidelity, simulator type, scenario, and team composition (Chiniara et al., 2013). The conceptual framework developed by Chiniara et al. (2013) includes many of the concepts described in Jeffries et al. (2016) and Aebersold and Titler (2014) work and, in addition, provides a clear decision-tree for informing the design of simulation for medical education. Chiniara and colleagues identify Kolb's (1984) and Ericsson's (2004) theories as relevant and appropriate for simulation. However, the emphasis on the educational medium and the simulation modality as the pivotal choices for simulation design means, again, there is minimal reference to the workplace learning theories necessary to create a simulated clinical placement which can legitimately replace a placement experience.

To date, most evidence in nursing and medical education literature supports the use of simulation for the development of procedural and clinical skills such as surgical and emergency procedures, many of which use high technology simulators (Cook et. al., 2011; Cant \& Cooper, 2017). Others have investigated specific simulation in training non-technical skills such as communication skills (Kaplonyi et.al., 2017) but it appears that no conceptual framework has been developed to guide the design and evaluation of a simulated clinical placement to fully replace a clinical placement. While many concepts included in the NLN Jeffries Simulation Theory and 
SMILHO are relevant to be included in a conceptual framework for simulated clinical placement, the relationship between the concepts may differ when placed in the context of placement replacement. In addition to the theories and concepts used by Jeffries et al. (2016) and Aebersold and Titler (2014), theories of authentic learning and workplace learning must also be considered if we are to replicate a clinical placement context holistically. Factors such as practice context and professional accreditation standards for clinical placements are other critical concepts to be considered in designing a simulated clinical placement as placement replacement.

\section{Developing a Conceptual Framework}

Bordage (2009, pp.313) defines conceptual frameworks as "ways of thinking about a problem or a study, or ways of representing how complex things work the way they do." Clinical practice and clinical fieldwork education are complex phenomena and a conceptual framework for simulating clinical placement is necessary for two reasons. First, the conceptual framework could be used to identify the activities and processes required to replicate a complex but coherent clinical placement experience, and second, the conceptual framework could be used to guide research on the effectiveness of a simulated placement to replace a traditional clinical placement experience. The aim of the conceptual framework presented in this paper, called the Conceptual Framework for Simulated Clinical Placement (CF-SCP), is to represent the concepts that underpin the design of a simulated clinical placement and draw together assumptions about the inter-relationship of these. The remainder of this

This article is protected by copyright. All rights reserved. 
paper describes the CF-SCP and the process undertaken to develop it. A brief description of a vocational rehabilitation SCP is provided as an example of applying the CF-SCP.

\section{Developing the CF-SCP}

The development of the CF-SCP reflected the recommendations of Bordage (2009) by comprising a synthesis of theories, models and evidence-based practices. Specifically, the CF-SCP aligns educational design principles, workplace learning theories and simulation theory, drawing on the experience of developing and implementing a one-week Simulated Clinical Placement (SCP) in the occupational therapy practice area of vocational rehabilitation. This vocational SCP was designed as 'placement replacement' in response to a need for clinical placement learning in this area. Each stage of the design and development of the SCP was informed and guided by iterative consultation and discussion among three groups of experts: those with clinical expertise in vocational rehabilitation, those with occupational therapy curricula expertise and those with simulation expertise. Thus, the process of developing the CF-SCP was based on simulation and learning theories and frameworks, integrated with expert opinion relevant to the local professional context. Following development and implementation of the vocational SCP, an emergent framework was constructed to support development of SCP in two other placement settings: mental health and physical rehabilitation. These SCP were also developed in

This article is protected by copyright. All rights reserved. 
consultation with clinical, curricula and simulation experts. This process served to highlight and reinforce the relevant theoretical and practical considerations required to formulate an SCP from which the CF-SCP evolved.

\section{The Components of the CF-SCP}

The CF-CSP comprises two parts: SCP Design Considerations and SCP Experience (Figure 1). Part one of the CF-SCP has three components which inform the SCP design: practice education to be considered in relation to the learner; criteria for quality simulation design; and theoretical perspectives which reflect the intended learning experience. First, the SCP designer must consider the elements of practice education such as practice context, practice process, learner level and learning outcomes which guide the simulation design in relation to the learner. Second, consideration must be given to the criteria for quality simulation design: authenticity, complexity, immediacy to practice, performance assessment and use of multiple modalities (Rodger et. al., 2010). Third, the theoretical perspectives of authentic and workplace learning relevant to the SCP context provide a theoretical bridge between university and workplace learning. In this case, Eraut's (2007) early career learning theory and Herrington and Oliver's (2000) authentic learning theory were applied.

Part two of the CF-SCP, the SCP Experience, is depicted as interconnecting learning activities and processes, and represents the dynamic components of simulation which collectively form the simulated clinical placement experience.

[INSERT FIGURE 1 HERE] 
NB. The Conceptual Framework for Simulated Clinical Placements (CF-SCP) has two parts. Part one: Design consideration has three components; one identifying the elements of practice education to be considered in relation to the learner, another which gives consideration to the criteria for quality simulation design and the third which identifies theoretical perspectives of authentic and workplace learning. Part two of the framework - SCP experience - depicts interconnecting learning activities and processes, which collectively form an SCP experience.

\section{Part One of the CF-SCP: Design Considerations}

\section{Elements of practice education.}

\section{Practice context.}

The goal of a simulated clinical placement is to replicate for students a learning experience embedded within practice. An essential first consideration is the identification and articulation of the practice to be simulated. The Occupational Therapy Board of Australia (2012) defines occupational therapy practice as "any role, whether remunerated or not, in which the individual uses skills and knowledge as a health practitioner in their health profession" (pp.1-2). According to the World Federation of Occupational Therapists (2016), "the purpose of practice education is to prepare students to become competent entry level practitioners who can function and thrive in a rapidly changing health and human services system" (p.48). In the context of occupational therapy practice education, students must gain a broad knowledge of human occupations and develop clinical reasoning skills that can deal with complexity and competence in client-centred occupational therapy practice. The practice context can relate to the clinical setting or the client population.

Practice process.

This article is protected by copyright. All rights reserved. 
The processes applicable to a specific area of practice affect the simulated clinical placement design. Pre-registration health professional curricula are based on specific theories and practice frameworks. Aligning the design of an SCP with a specific theory or framework can facilitate student learning through experiencing the application of such perspectives rather than learning through reading or discussion. In occupational therapy, the Canadian Practice Process Framework (CPPF) (Craik, Davis \& Polatajko, 2007) provides a generic, structured practice framework for evidence-based client-centred therapy that can be applied in diverse practice contexts. The CPPF describes the dynamic interchange between client and therapist when developing and evaluating actions plans. This framework includes eight action points: 1. Enter / initiate; 2 . Set the stage; 3 . Assess/evaluate; 4. Agree - objectives and plan; 5. Implement plan; 6. Monitor/ modify; 7. Evaluate outcome and 8. Conclude/Exit. The learner level and learner outcomes guide the selection of the appropriate action points for the design of the simulation in question.

Learner level.

The knowledge, skill and experiences of a learner influence the design of an SCP. Consideration of the discipline-specific knowledge, skills and prior experiences informs the types of experiences to be simulated (International Nursing Association for Clinical Simulation and Learning (INACSL) Standards Committee, 2016a). Consideration of previous simulation activities learners have experienced, informs the modalities of simulation and the level of facilitation employed (Fanning \& Gaba, 2007; Kelly \& Guinea, 2018). 


\section{Learning outcomes.}

Learning outcomes provide the foundation and framework for sound educational design (Arthur, Levett-Jones \& Kable, 2013; INACSL Standards Committee, 2016b; Levett-Jones \& Guinea, 2017). In an SCP experience, there is an imperative that learning outcomes are practice-based. Logically, learning outcomes for an SCP experience should be similar to, if not the same as, those for traditional clinical placement.

\section{Quality Criteria.}

Significant advances have been made in the development of criteria for quality simulation practice in nursing (Arthur et al., 2013; INACSL Standards Committee, 2016c) and in medical simulation (Issenberg, McGhaghie, Petrusa, Gordon \& Scalese, 2005; Motola, Devine, Chung, Sullivan \& Issenberg, 2013). However, there is a paucity of quality criteria when the aim is to design a coherent simulation experience as a replacement for clinical placement hours.

In 2010, Rodger et al. published five criteria to be addressed when the aim is to replace clinical placement hours with simulation in pre-registration occupational therapy education. Accreditation standards for Australian Occupational Therapy education programs (Occupational Therapy Council, Australia \& New Zealand, 2013a, 2013b) allow for $20 \%$ of the required 1000 hours of clinical placement to be replaced with simulation experiences providing these five criteria are met. Developed in Australia through a process of national consultation, the five criteria (see Box 1 and Figure 1) shift the focus from broad conceptualisations of occupational therapy 
practice, to the design of simulation learning experiences for students and guide the design of SCP experiences.

\section{[INSERT BOX 1 HERE]}

\section{Learning Theory.}

Learning theory provides designers of simulation with a lens through which to understand how learning occurs (e.g., cognitive, constructivist, sociocultural perspectives) and when and where learning occurs (formally or informally, classroom or workplace) (INACSL Standards Committee, 2016a; Levett-Jones \& Guinea, 2017). Whilst simulation is often designed to replicate situations from the perspective of experienced practitioners, SCP requires students to develop a repertoire of practice skills and mirror the activities and processes students would undertake on traditional placement in a similar context. They have the opportunity to learn their role as students of occupational therapy in a formative and supportive environment which must, nevertheless, consider the work processes and activities required in a traditional setting. These design choices within the SCP can be informed by the theoretical perspectives of Herrington and Oliver (2000) and Eraut (2007). Herrington and Oliver identified nine elements they deemed critical in the design of authentic learning environments and experiences. These are presented in Box 2 and Figure 1.

[INSERT BOX 2 HERE]

This article is protected by copyright. All rights reserved. 
These elements inform the design of an SCP so that it incorporates authentic learning within the practice context and aligns with the quality criteria (Roger et al., 2010) required if replacing professional practice hours. Research into early career professional learning showed that most workplace learning is embedded in everyday work rather than in formal teaching (Eraut, 2007). Eraut developed a typology of early career learning which classified learning processes according to whether their principle objective was working or learning. This typology (see Table 1) comprised three processes: work processes with learning as a by-product; learning activities located within work or learning processes; and learning processes at or near the workplace (Eraut, 2007).

\section{[INSERT TABLE 1 HERE]}

Conceptually the elements of practice education provide the focus for the SCP. These must then be developed according to quality criteria for simulation design, and underpinned by learning theories aligned to the desired SCP experience for the learner.

\section{Part Two of the CF-SCP: SCP Experience}

Part two of the CF-SCP depicts interconnecting learning activities and processes, which collectively form a simulated clinical placement experience. These are depicted as a honeycomb, portraying the complex interactions that occur among

This article is protected by copyright. All rights reserved. 
the different elements as the learner engages with the activities and processes embedded in the placement experience. The designed learning experience is the result of the application of the SCP design considerations (part one of the CF-SCP), and relies on the integration of the learning activities to provide a holistic experience capable of replacing clinical placement. Six elements (see Figure 1) were identified as important to an SCP placement experience from the practical experience of designing an SCP, review of key literature in simulation and practice-based learning.

\section{Case scenarios.}

Case scenarios in the $\mathrm{CF}-\mathrm{SCP}$ form the basis of the learning experience for the students. According to Shea (2015), scenarios in simulation for occupational therapy education should be based on the learning objectives of the experience and the clinical environment relevant to the simulation, and include the client's physical, mental and social factors relevant to the scenario. The scenario should be based at a specific stage of the client's medical or rehabilitation journey which should be closely related to the learning level of the students working with the scenario. The environment needs to replicate the clinical setting as far as possible. Case scenarios in simulation may include the use of simulated patients, for whom scripts may be developed to ensure standardised experiences for students undertaking the simulation (Shea, 2015).

\section{Simulated patients and key stakeholders.}

Simulated patients are a simulation modality where a person takes on the role of a patient or client, and guides the simulation to achieve student learning outcomes (Churchouse \& McCafferty, 2012; Nestel \& Bearman, 2015). Simulated patients or

This article is protected by copyright. All rights reserved. 
simulated participants (Nestel, Sanko \& McNaughton, 2018) provide the opportunity for students to interact in a realistic manner with real people who assume a condition or behaviour that the student would be likely to encounter on clinical placement. Shea (2015) noted that the use of simulated patients creates a standardised experience for students, and provides a means for students to receive feedback about their performance from the perspective of the patient. This enhances the likelihood that the students will suspend disbelief, perceive the situation to be realistic and engage accordingly (Kaplonyi et al., 2017). Simulated patients allow practice at developing skills in interpersonal interactions including interview skills (Kaplonyi et al., 2017; Sabus \& Macauley, 2016). Simulated patient methodology is used in the CF-SCP to enhance the authenticity of interactions between students, clients and stakeholders (Herrington \& Oliver, 2000; Nestel, Sanko \& McNaughton, 2018; Rodger et al., 2010). Depending on the case scenario, stakeholders may include a client's next of kin, general practitioner, treating therapist or employer.

\section{Simulated environments, systems, tools \& processes.}

Simulated environments, including tools and processes, are paramount to creating an authentic simulated practice setting (Herrington \& Oliver, 2000). The simulation environment needs to be authentic enough to facilitate the immersion of students in the experience. Immersion can be enhanced physically (by authentically replicating the physical environment and the tools and processes of work necessary in actual practice), conceptually (by authentically replicating the cognitive processes used for sound decision-making in the designed situation), and psychologically (by 
authentically replicating the roles of healthcare professionals) (Guinea, 2016;

Herrington \& Oliver, 2000; Sabus \& Macauley, 2016).

Authentic student performance assessment.

According to principles of constructive alignment (Biggs \& Tang, 2011), and as reflected in the criteria of Rodger et al. (2010) and Herrington and Oliver (2000), assessment is an essential element for an authentic learning experience in an SCP. At the very core of an SCP designed to replace placement is the intent to authentically replicate professional practice placement elements. An important question becomes whether students can achieve the same learning outcomes and professional competencies that they would be expected to achieve on a traditional placement. Thus, a standard method of measuring professional competence is an important element of the SCP and it follows that tools used for evaluating student competence during traditional placements should also be used during simulated placements. The assessment tool must align with the types of activities and work processes students need to experience to demonstrate the application of knowledge and skill during the SCP. In the context of occupational therapy education in Australian universities, the Student Practice Evaluation Form-Revised Edition (SPEF-R) (Allison \& Turpin, 2004) or a modified shorter version, the SPEF-R short version are commonly used to assess student competency. Thus, assessment is emphasised in the CF-SCP (part one and part two) and the SPEF-R short version chosen as most applicable for a short placement experience in the Australian context.

\section{Debriefing and reflection.}

This article is protected by copyright. All rights reserved. 
Simulation debriefing is a "facilitated or guided reflection in the cycle of experiential learning" (Fanning \& Gaba, 2007). Debriefing contributes significantly to learning from simulation experiences (Cheng, Eppich, Grant, Sherbino, Zendejas \& Cook, 2014; Levett-Jones \& Lapkin, 2014). Best practice guidelines for healthcare simulation recommend that the debrief is structured and is based on a theoretical framework congruent with the objectives and intended learning outcomes for the simulation (Arthur et al, 2013; INACSL Standards Committee, 2016d). Boud, Keogh and Walker (1985) define reflection as "intellectual and affective activities in which individuals engage to explore their experience in order to lead to new understanding and appreciations" (p.3). Reflection is perceived as essential in the development of professional competencies in health professional education (Cantrell, 2008). Whether during clinical placement or simulation-based learning, reflection and reflective learning in health professional education may be facilitated by clinical supervisors or educators. However, in some cases, these individuals may not be experienced at stimulating higher-order reflective thinking with effective questioning (Husebø, Dieckmann, Rystedt, Søreide \& Friberg, 2013; Philips \& Duke, 2001; Philips, Duke \& Weeruriya, 2017). Furthermore, considering when, where and how debriefing is to occur during an extended period, as is the case for an SCP experience, requires consideration of models, timing and spaces for debriefing to occur during an SCP that reflect the realities of an authentic clinical placement (Eraut, 2007; Herrington \& Oliver, 2000). Accordingly, the CF-SCP requires opportunities for facilitated 
reflective learning through debriefing at scheduled and unscheduled times, and in formal and informal spaces, as reflected in the CF-SCP framework.

\section{Facilitation and Clinical supervision.}

Understanding the process of facilitation and consideration of the role of the facilitator as a part of simulation design is of great importance to ensure the desired student learning experience (Kelly \& Guinea, 2018). For an SCP, the role of the facilitator is one of a clinical supervisor and the process of facilitation must reflect that of learning during an authentic clinical placement experience situated in an authentic practice (Eraut, 2007; Herrington \& Oliver, 2000).

\section{CF-SCP Exemplar: SCP for Vocational Rehabilitation}

The activities and processes of a Vocational Rehabilitation SCP were designed to replicate the student experience of a traditional 40-hour (one-week) placement in a vocational rehabilitation setting. Case studies that reflected common vocational rehabilitation referrals were developed by synthesising recommendations from expert consultants with university curriculum requirements and design principles of the SCP. Each case study was developed as a complete scenario package comprising facilitator resources for the implementation of the SCP, and elements of practice that provided context for each case, with which students engaged as a fundamental part of the SCP. Case studies and the respective scenario package resources were endorsed as authentic representations of practice by expert consultants.

This article is protected by copyright. All rights reserved. 
The aim of the SCP was to facilitate learning that was challenging but achievable, relevant and meaningful. Accordingly, activities were scaffolded across the week progressing from simple to more complex, in a way that represented authentic practice. A description of the activities and processes of the SCP is provided in Box 3. Throughout the SCP, actors (simulated patients/clients), clinicians and academic staff were engaged to play the roles of the client and other stakeholders. Students were required to interact with these stakeholders in a sequence that replicated real practice and required them to immerse themselves in the interactions with the actors to gain experience in formulating decisions as part of the clinical process. These design elements were necessary to create a sense of immediacy between the learning opportunities the simulated workplace might provide with the interaction with simulated clients, real clinical supervisors and real worksites. Clinicians experienced in vocational rehabilitation were employed as clinical supervisors; simulation facilitators were engaged to support debriefing and reflection; and the clinical supervisors and simulation facilitators were responsible for administering a modified version of SPEF-R (Allison \& Turpin, 2004) to assess students' performance.

[INSERT BOX 3 HERE]

The SCP used a range of simulation modalities including written and video case studies, simulated patients, teacher-in-role, a simulated workplace with associated 
resources, and authentic practice-based activities, integrated to simulate actual practice experiences.

\section{Discussion}

This paper presents the CF-SCP for designing simulated clinical placement to replace placement in an undergraduate occupational therapy degree. The SCP designed using the CF-SCP differs from previous simulation-based learning experiences which have tended to replicate brief snapshots of practice. The CF-SCP allows for the development of an authentic, coherent SCP experience designed to unfold over an extended period and include activities and processes to replicate traditional placement experiences. The inclusion of quality criteria for simulation to replace clinical placement hours (Rodger et al., 2010) in the CF-SCP can support the application of the framework to varied practice contexts and create authentic experiences of comparable value to traditional placements. Best practice guidelines for healthcare simulation (INACSL Standards Committee, 2016c; Motola, et al., 2013) and theoretical models of simulation (Jeffries et al., 2016) highlight the importance of informing simulation design with theoretical perspectives that align with the purpose and population of the simulation experience. However, simulating a clinical placement requires more than replicating a series of individual tasks. It requires a replication of the sociocultural context and processes of practice. Simulations designed according to theoretical perspectives of workplace learning (such as Herrington \& Oliver, 2000; Eraut, 2007) go beyond simple perceptions of 
constructivism by considering the how, when and where learning occurs during clinical placement. This makes possible the replication of everyday workplace situations, practices and processes and reflects the intent of contemporary perspectives by aligning classroom and workplace learning (Billett, 2011; Billett \& Henderson, 2011; Boud, 2012).

An SCP designed according to the CF-SCP, can ensure that interactions with clients are embedded within the context of practice. Developing simulation that represents coherent practice requires realistic interactions between students and simulated clients, including preparation for interactions with clients, interpreting data obtained from such interactions, and bringing together multiple data sources from a range of stakeholders to achieve an agreed objective. Findings of Bethea, Castillo and Harvison (2014, p.S35) support this claim with occupational therapy program faculty reporting perceived strengths of simulation as including "an opportunity to develop safety with clients, practice clinical skills, use clinical reasoning and critical thinking, prepare for fieldwork, and facilitate concept integration".

Simulation as a learning and teaching method is still emerging in allied health education providing opportunities for innovative approaches to be developed, particularly in relation to preparing students for later years or long-block professional practice placements. However, it is necessary to situate these learning opportunities within a conceptual framework that aligns to substantive workplace learning theories and can be applied with consistency across many practice areas. Despite the benefits of being able to provide an authentic, safe, consistent and engaging learning 
experience for students, implementing a simulated professional practice experience is not likely to be without its challenges. Developing a highly authentic and complex SCP requires significant time to develop materials, learning environments and provide staff training. Staff training is essential to ensure students are immersed in an authentic environment where the primary focus is participation in practice with learning as an outcome. Concerns about the potential high cost of developing and implementing simulation-based programs and providing training to staff to implement them cannot be ignored.

Evidence about the contribution simulation makes to improving learning outcomes for students is required (Bethea et al, 2014; Hamilton et. al., 2015). Preliminary evidence suggests that SCPs have the potential to partially replace traditional professional practice placement and studies are required that provide the empirical evidence that support this in occupational therapy education. There is an urgent need for rigorous research to evaluate effectiveness of simulation in occupational therapy and to gauge the cost-effectiveness. The CF-SCP described in this paper advances simulation based learning by integrating principles of simulation with theoretical perspectives of learning, particularly workplace learning, to replicate a coherent practice experience. The CF-SCP can be used to develop experiences to partially substitute clinical placements and future research is required to evaluate the effectiveness of this approach to simulation (Imms et al., 2017).

\section{Conclusion}

This article is protected by copyright. All rights reserved. 
The CF-SCP provides a framework to develop simulation experiences that are grounded in learning theory and adhere to quality criteria for the substitution of a complete clinical placement. The CF-SCP enables future researchers to design, implement and evaluate simulation as 'placement replacement' across a range of occupational therapy practice areas and other health disciplines. Situating the design of replacement SCPs within theoretical constructs will enable research into the effectiveness and cost comparison between SCP and traditional clinical placement.

This article is protected by copyright. All rights reserved. 


\section{Acknowledgement}

We would like to acknowledge the members of the Occupational Rehabilitation Specialist Interest Group of Occupational Therapy Australia Ltd. (Victoria Division) who participated in the consultation process.

This project received funding from the Australian Government Department of Health.

This article is protected by copyright. All rights reserved. 


\section{References}

Aebersold, M. \& Titler, M. G. (2014). A simulation model for improving learner and health outcomes. The Nursing Clinics of North America, 49(3), 431-439. doi: 10.1016/j.cnur.2014.05.011

Aldrich, C. (2009). The complete guide to simulation and serious games. San Francisco, CA: John Wiley \& Sons.

Allison, H., \& Turpin, M. J. (2004). Development of the student placement evaluation form: A tool for assessing student fieldwork performance. Australian Occupational Therapy Journal, 51(3), 125-132. doi: 10.1111/j.14401630.2004.00414.x

Arthur, C., Levett-Jones, T., \& Kable, A. (2013). Quality indicators for the design and implementation of simulation experiences: A Delphi study. Nurse Education Today, 33(11), 1357-1361. doi: 10.1 016/j.nedt.2012.07.012

Bethea, D. P., Castillo, D. C., \& Harvison, N. (2014). Use of simulation in occupational therapy education: Way of the future? American Journal of Occupational Therapy, 68(Suppl.), S32-39. doi: 10.5014/ajot.2014.012716

Billett, S. (2011). Integrating experiences in university and practice settings: A conceptual perspective. In S. Billett \& A. Henderson (Eds.), Developing learning professionals: Integrating experiences in university and practice settings (pp. 21-40). Dordrecht, The Netherlands: Springer.

Billett, S., \& Henderson, A. (2011). Promoting professional learning: Integrating experiences in university and practice settings. In S. Billett \& A. Henderson (Eds.), Developing learning professionals: Integrating experiences in university and practice settings (pp. 1-19). Dordrecht, The Netherlands: Springer.

Biggs, J. \& Tang, C. (2011) Teaching for quality learning at university (4 ${ }^{\text {th }} \mathrm{ed}$.). Maidenhead, United Kingdom: McGraw-Hill / Society for Research into Higher Education \& Open University Press

Bordage, G. (2009). Conceptual frameworks to illuminate and magnify. Medical Education, 43(4), 312-319. doi: 10.1111/j.1365-2923.2009.03295.x

This article is protected by copyright. All rights reserved. 
Boud, D. (2012). Problematising practice-based education. In J. Higgs, R. Barnett, S. Billett, M. Hutchings, \& F. Trede (Eds.), Practice-based education: Perspectives and strategies. Rotterdam, The Netherlands: SensePublishers

Boud, D., Keogh, R. \& Walker, D. (1985). Reflection: Turning experience into learning. London, United Kingdom: Kogan Page

Cant, R. \& Cooper, S. (2017). Use of simulation-based learning in undergraduate nurse education: An umbrella systematic review. Nurse Education Today, 49, 63-71. doi: 10.1016/j.nedt.2016.11.015

Cantrell, M. A. (2008). The importance of debriefing in clinical simulations. Clinical Simulation in Nursing (4)2, e19-e23

Cheng, A., Eppich, W., Grant, V., Sherbino, J., Zendejas, B. \& Cook, D. A. (2014). Debriefing for technology-enhanced simulation: A systematic review and meta-analysis. Medical Education, 48(7), 657-666. doi: 10.1111/medu.12432

Chiniara, G., Cole, G., Brisbin, K., Huffman, D., Cragg, B., Lamacchia, M., ... Canadian Network for Simulation in Healthcare Guidelines Working Group (2013). Simulation in healthcare: A taxonomy and a conceptual framework for instructional design and media selection. Medical Teacher, 35(8), e1380e1395. doi: /10.3109/0142159X.2012.733451

Churchouse, C. \& McCafferty, C. (2012). Standardized patients versus simulated patients: Is there a difference? Clinical Simulation in Nursing, 8(8), e363e365. doi: 10.1016/j.ecns.2011.04.008

Cook, D. A., Hatala, R., Brydges, R., Zendejas, B., Szostek, J. H., Wang, A. T. ... Hamstra, S. J. (2011). Technology-enhanced simulation for health professions education. A systematic review and meta-analysis. JAMA, 306(9), 978-988. doi: 10.1001/jama.2011.1234

Craik, J., Davis, J., \& Polatajko, H. J. (2007). Introducing the Canadian Practice Process Framework (CPPF): Amplifying the context. In E, A. Townsend \& H. J. Polatajko (Eds.). Enabling occupation II: Advancing an occupational therapy vision of health, well-being, \& justice trough occupation (pp. 229246). Ottawa, Canada: CAOT Publications.

This article is protected by copyright. All rights reserved. 
Eraut, M. (2007). Learning from other people in the workplace. Oxford Review of Education, 33(4), 403-422. doi: 10.1080/03054980701425706

Ericsson, K. A. (2004). Deliberate practice and the acquisition and maintenance of expert performance in medicine and related domains. Academic Medicine, 79(Suppl 10), S70-S81. doi: 10.1097/00001888-200410001-00022

Ericsson, K. A. (2008). Deliberate practice and acquisition of expert performance: A general overview. Academic Emergency Medicine, 15(11), 988-994. doi: $10.1111 / \mathrm{j} .1553-2712.2008 .00227 . \mathrm{x}$

Fanning, R. M., \& Gaba, D. (2007). The role of debriefing in simulation-based learning. Simulation in Healthcare, 2(2), 115-125. doi: 10.1097/SIH.0b013e3180315539

Gaba, D. M. (2004) The future vision of simulation in health care. Quality \& Safety Health Care, 13(Suppl 1), i2-i10. doi:10.1136/qshc.2004.009878

Guinea, S. (2016). Employing Communities of Practice to Facilitate International Culturally and Linguistically Diverse Nursing Students' Identities as Learners in Australia through Immersive Simulation. Doctoral dissertation. Melbourne, Australia: Monash University. Retrieved from https://doi.org/10.4225/03/58b8a724a41ba

Hager, P. (2011). Theories of workplace learning. In M. Malloch, L. Cairns, K. Evans \& B. O'Connor (Eds.), The SAGE handbook of workplace learning (pp. 1731). London, United Kingdom: SAGE Publications Inc.

Hamilton, A., Copley, J., Thomas, Y., Edwards, A., Broadbridge, J., Bonassi, M., ... Newton, J. (2015). Responding to the growing demand for practice education: Are we building sustainable solutions? Australian Occupational Therapy Journal, 62(4), 265-270. doi: 10.1111/1440-1630.12181

Hayden, J., Smiley, R. A., Alexander, M. \& Kardong-Edgren, S. (2014). The NCSBN National Simulation Study: A longitudinal, randomized, controlled study replacing clinical hours with simulation in prelicensure nursing education. Journal of Nursing Regulation, (5)2, S3-40. doi: 10.1016/S2155$8256(15) 30062-4$

This article is protected by copyright. All rights reserved. 
Herrington, J., \& Oliver, R. (2000). An instructional design framework for authentic learning environments. Educational Technology, Research and Development, 48(3), 23-48.

Hill, A. Davidson, B., \& Theodoros, D. (2013). Speech-language pathology students' perceptions of a standardised patient clinic. Journal of Allied Health, 42(2), 84-91. Retrieved from http://www.asahp.org/journal-of-allied-health/

Husebø, S. E., Dieckmann, P., Rystedt, H., Søreide, E. \& Friberg, F. (2013). The relationship between facilitators' questions and the level of reflection in postsimulation debriefing. Simulation in Healthcare, 8(3), 135-142. doi: 10.1097/SIH.0b013e31827cbb5c

Imms, C., Chu, E., Guinea, S., Sheppard, L., Froude, E., \& Carter, R. (2014). National Consultation Report - Embedding Simulation in Occupational Therapy. A project funded by Health Workforce Australia. Melbourne, Australia: Australian Catholic University.

Imms, C., Chu, E. M. Y., Guinea, S., Sheppard, L., Froude, E., Carter, R., ... Symmons, M. (2017). Effectiveness and cost-effectiveness of embedded simulation in occupational therapy clinical practice education: Study protocol for a randomised controlled trial. Trials, 18(1). doi: 10.1186/s13063-017-2087-0 International Nursing Association for Clinical Simulation and Learning Standards Committee. (2016a). Standards of best practice: Simulation ${ }^{\text {SM }}$. Simulation design. Clinical Simulation in Nursing, 12(Suppl), S5-S12. doi: 10.1016/j.ecns.2016.09.005

International Nursing Association for Clinical Simulation and Learning Standards Committee. (2016b). Standards of best practice: Simulation ${ }^{\text {SM }}$. Outcomes and objectives. Clinical Simulation in Nursing, 12(Suppl), S13-S15. doi: 10.1016/j.ecns.2016.09.006

International Nursing Association for Clinical Simulation and Learning Standards Committee. (2016c). Standards of best practice: Simulation ${ }^{\text {SM }}$. Retrieved from https://www.inacsl.org/i4a/pages/index.cfm?pageid=3407

This article is protected by copyright. All rights reserved. 
International Nursing Association for Clinical Simulation and Learning Standards Committee. (2016d). Standards of best practice: Simulation ${ }^{\text {SM }}$. Debriefing. Clinical Simulation in Nursing, 12(Supp1), S21-S25. doi: 10.1016/j.ecns.2016.09.008

Issenberg, S. B., McGaghie, W. C., Petrusa, E. R., Gordon, D. L., \& Scalese, R. J. (2005). Features and uses of high-fidelity medical simulations that lead to effective learning: A BEME systematic review. Medical Teacher, 27(1), 1028. doi: 10.1080/01421590500046924

Jeffries, P., Rodgers, B, \& Adamson, K. A. (2016). NLN Jeffries Simulation Theory: Brief narrative description. In P. Jeffries (Ed.). The NLN Jeffries Simulation Theory (pp.39-42). Philadelphia, PA: Wolters Kluwer

Kaplonyi, J., Bowles, K.-A., Nestel, D., Kiegaldie, D., Maloney, S., Haines, T. \& Williams, C. (2017). Understanding the impact of simulated patients on health care learners' communication skills: A systematic review. Medical Education, 51(12), 1209-1219. doi: 10.1111/medu.13387

Kelly, M. \& Guinea, S. (2018). Facilitating healthcare simulations. In D. Nestel, M. Kelly, B. Jolly \& M. Watson (Eds.). Healthcare simulation education: Theory, evidence and practice (1st ed.) (pp. 143-151). Chichester, United Kingdom: Wiley Blackwell

Kolb, D. A. (1984). Experiential learning: Experience as the source of learning and development. Upper Saddle River, NJ: Prentice-Hall.

Lavoie, P., Michaud, C., Bélise, M., Boyer, L., Gosselin, E., Grondin, M. ... Pepin, J. (2018). Learning theories and tools for the assessment of core nursing competencies in simulation: A theoretical review. Journal of Advanced Nursing, 74(2), 239-250. doi: 10.1111/jan.13416

Levett-Jones, T. \& Guinea, S. (2017). The evolution of a mnemonic for quality simulation practices. Clinical Simulation in Nursing, 13(11), 552-561. doi: 10.1016/j.ecns.2017.07.004

This article is protected by copyright. All rights reserved. 
Levett-Jones, T. \& Lapkin, S. (2014). A systematic review of the effectiveness of simulation debriefing in health professional education. Nurse Education Today, 34(6), e58-e63. doi: 10.1016/j.nedt.2013.09.020

Motola, I., Devine, L. A., Chung, H. S., Sullivan, J. E., \& Issenberg, S. B. (2013). Simulation in healthcare education: A best evidence practical guide. AMEE guide No. 82. Medical Teacher, 35(10), e1511-e1530. doi:

10.3109/0142159X.2013.818632.

Nestel, D. \& Bearman, M. (2015). Introduction to simulated patient methodology. In D. Nestel \& M. Bearman (Eds.). Simulated patient methodology: Theory, evidence and practice (pp.1-4). Chichester, United Kingdom: Wiley Blackwell Nestel, D., Sanko, J. \& McNaughton, N. (2018). Simulated participant methodologies: Maintaining humanism in practice. In D. Nestel, M. Kelly, B. Jolly \& M. Watson (Eds.). Healthcare simulation education: Theory, evidence and practice (1st ed.) (pp. 45-53). Chichester, United Kingdom: Wiley Blackwell

Occupational Therapy Board of Australia (2012) Registration standards for occupational therapy: Recency of practice. Retrieved from http://www.occupationaltherapyboard.gov.au/Registration-Standards.aspx

Occupational Therapy Council (Australia \& New Zealand) (2012) Annual report. Retrieved from http://otcouncil.com.au/annual-report Occupational Therapy Council (Australia \& New Zealand) (2013a). Occupational Therapy Council Accreditation Standards: Explanatory Guide: Use of Simulation in Practice Education / Fieldwork. Retrieved from http://otcouncil.com.au/accreditation

Occupational Therapy Council (Australia \& New Zealand). (2013b). Accreditation Standards for Entry-Level Occupational Therapy Education Programs. Retrieved from http://otcouncil.com.au/accreditation/ Occupational Therapy Council (Australia \& New Zealand) (2015) Annual report. Retrieved from http://otcouncil.com.au/annual-report

This article is protected by copyright. All rights reserved. 
Oppermann, R., \& Specht, M. (2006). Situated learning in the process of work. In D. Hung \& M. S. Khine (Eds.), Engaged learning with emerging technologies (pp. 69-89). Dordrecht, The Netherlands: Springer.

Philips, N., \& Duke, M. (2001). The questioning skills of clinical teachers and preceptors: A comparative study. Journal of Advanced Nursing, 33(4), 523529. doi: 10.1046/j.1365-2648.2001.01682.x

Philips, N., Duke, M. \& Weerasuriya, R. (2017). Questioning skills of clinical facilitators supporting undergraduate nursing students. Journal of Clinical Nursing, doi: 10.1111/jocn.13761

Rodger, S., Bennett, S., Fitzgerald, C. \& Neads, P. (2010). Use of simulated learning activities in occupational therapy curriculum: Final report. University of Queensland on behalf of Health Workforce Australia.

Rodger, S, Webb G, Devitt L, Gilbert J, Wrightson P, \& McMeeken J. (2008). Clinical education and practice placements in the allied health professions: An international perspective. Journal of Allied Health. 37, 53-62. Retrieved from http://www.asahp.org/journal-of-allied-health/

Rizzolo, M. A., Durham, C. F., Ravert, P. K., Jeffries, P. (2016). History and evolution of the NLN Jeffries Simulation Theory. In P. Jeffries (Ed.). The NLN Jeffries Simulation Theory (pp.1-8). Philadelphia, PA: Wolters Kluwer

Sabus, C. \& Macauley, K. (2016). Simulation in physical therapy education and practice: Opportunities and evidence-based instruction to achieve meaningful learning outcomes. Journal of Physical Therapy Education, 30(1), 3-13

Shea, C-K. (2015). High-fidelity simulation: A tool for occupational therapy education. The Open Journal of Occupational Therapy, 3. Retrieved from http://scholarworks.wmich.edu/ojot/

Shoemaker, M., Beasley, J., Cooper, M., Perkins, R., Smith, J., \& Swank, C. (2011). A method for providing high-volume interprofessional simulation encounters in physical and occupational therapy education programs. Journal of Allied Health, 40(1), e15-e21. Retrieved from http://www.asahp.org/journal-ofallied-health/

This article is protected by copyright. All rights reserved. 
Smith, P., Corso, L., \& Cobb, N. (2010). The perennial struggle to find clinical placement opportunities: A Canadian national survey. Nurse Education Today, 30(8), 798-803. doi: 10.1016/j.nedt.2010.02.004

Stratton, B., Lee, E., Bramble, M., Eccleston, C., McCall, M., Lucas, P. \& Robinson, A. (2015). Residential aged care facility clinical placements for undergraduate paramedic students: An evaluation of the Australian experience. Australasian Journal of Paramedicine, 12(2). Retrieved from https://ajp.paramedics.org/index.php/ajp

Watson, K., Wright, A., Morris, N., McMeeken, J., Rivett, D., Blackstock, F., ... Jull, G. (2012). Can simulation replace part of clinical time? Two parallel randomised controlled trials. Medical Education, 46(7), 657-667. doi: 10.1111/j.1365-2923.2012.04295.x

World Federation of Occupational Therapists (2016). Minimum standards for the education of occupational therapists-revised 2016. Forrestfield, WA: WFOT.

This article is protected by copyright. All rights reserved. 


\section{SCP Design Considerations}

\section{Elements of \\ Practice Education}

Practice

Context

Practice

Process

Learner

Level

Learning

Outcomes

Quality Criteria (Rodger et al 2010)

\begin{tabular}{|c} 
Authenticity \\
Complexity \\
\hline
\end{tabular}

Immediacy to Practice

Practice Performance Assessment

Multiple Simulation Modalities

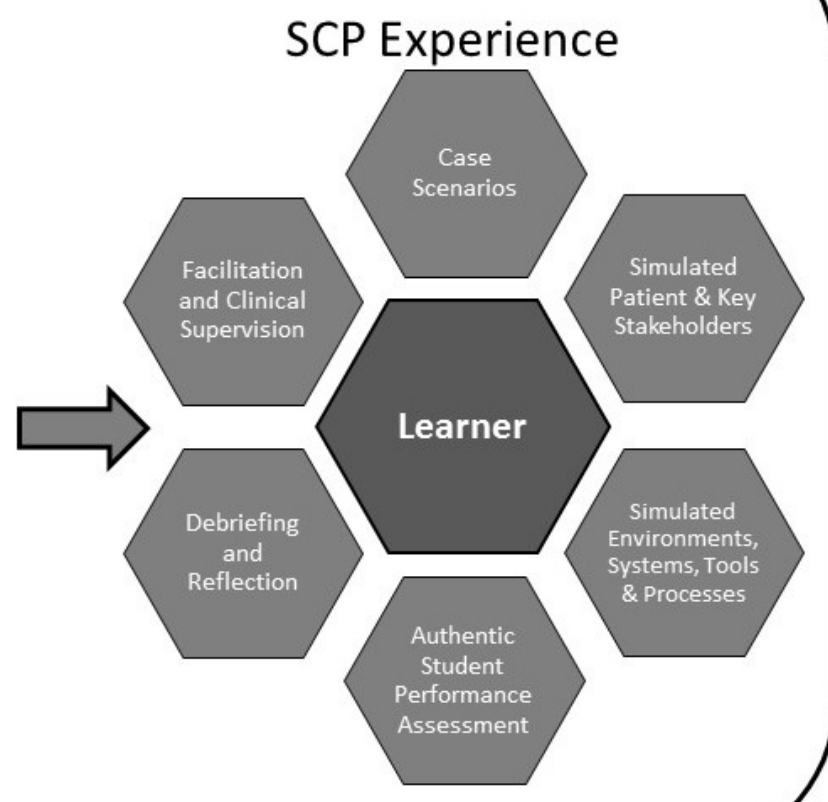

Figure 1 The Conceptual Framework for Simulated Clinical Placements (CF-SCP)_revised.jpg

This article is protected by copyright. All rights reserved. 
Box 1. Criteria for quality simulation (Rodger, Bennett, Fitzgerald and Neads, 2010, p. 6)

1. High level of authenticity for occupational therapy practice.

2. High level of complexity requiring student engagement and interaction.

3. Immediacy to interaction with a real client (who may be portrayed by a standardised patient) and to occupational therapy clinical placements.

4. Assessed with respect to meeting occupational therapy clinical placement objectives.

5. No one simulation modality used as a 'standalone' alternative to clinical training time. 
Box 2. Design elements for authentic learning environments (Herrington \& Oliver, 2000, p. 25-26)

1. Provide authentic contexts that reflect the way that knowledge will be used in real life.

2. Provide authentic tasks and activities.

3. Provide access to expert performances and the modelling of processes.

4. Provide multiple roles and perspectives.

5. Support collaborative construction of knowledge.

6. Promote reflection to enable abstractions to be formed.

7. Promote articulation to enable tacit knowledge to be made explicit.

8. Provide coaching and scaffolding by the teacher at critical times.

9. Provide for authentic assessment of learning within the tasks. 
Day One: To create an authentic workplace atmosphere, students attended an orientation to the simulated vocational rehabilitation agency created on the university campus. This required both a physical space (rooms in the University) and a virtual space (web-based intranet). Students were briefed on the expected professional behaviour and work procedures during the SCP. One clinical supervisor and one simulation facilitator were responsible for supervising students, providing an orientation to the simulated return to work agency, the client referrals, and preparation for student-stakeholder interviews, assessments and communications skills scheduled for the following day. Practicing vocational rehabilitation consultants took the role of the clinical supervisors.

Day Two: Students conducted an initial assessment with a client (simulated patient), and gathered necessary information via telephone interviews from medical and allied health practitioners, employers, family members relevant to the client.

Day Three: A site visit to a real workplace was included in the design to provide an authentic environment as the simulated client's workplace. During the site visit, students performed the role of a vocational rehabilitation case manager, gathering and documenting information by conducting workplace assessments in real workplaces where they could observe a worker performing duties similar to the ones their simulated client would undertake. Workplace assessment forms a critical component of the occupational rehabilitation process and a visit to a real workplace was designed to provide opportunities for students to engage in authentic assessments supported by their clinical supervisors. Workplaces were situated close to the university in a local hospital or community to provide immediacy between the interviews with the simulated client and the opportunity to situate the client in a real workplace (in line with the third of Rodger et al.'s (2010) criteria).

Day Four: Required students to analyse and interpret the information collected. The outcome of this day was for students to apply their knowledge and skills to formulate a return to work plan for the client.

Day Five: On the final day of the SCP, students presented their client's case history and intervention plan to their clinical supervisors and other students participating in the SCP similar to a case conference typically seen in vocational rehabilitation settings during which therapists present intervention plans to their client and the client's employer.

Box 3 Description of SCP activities and processes 
Table 1 A Typology of Early Career Learning (Eraut, 2007, p. 409)

\begin{tabular}{|c|c|c|}
\hline $\begin{array}{l}\text { Work processes with } \\
\text { learning as a by-product }\end{array}$ & $\begin{array}{l}\text { Learning activities located } \\
\text { within work or learning } \\
\text { processes }\end{array}$ & $\begin{array}{l}\text { Learning processes } \\
\text { at or near the workplace }\end{array}$ \\
\hline $\begin{array}{l}\text { Participation in group } \\
\text { processes. } \\
\text { Working alongside others. } \\
\text { Consultation. } \\
\text { Tackling challenging } \\
\text { tasks and roles. } \\
\text { Problem solving. } \\
\text { Trying things out. } \\
\text { Consolidating, extending } \\
\text { and refining skills. } \\
\text { Working with clients. }\end{array}$ & $\begin{array}{l}\text { Asking good questions. } \\
\text { Getting information. } \\
\text { Locating resource people. } \\
\text { Listening and observing. } \\
\text { Reflecting. } \\
\text { Learning from mistakes. } \\
\text { Giving and receiving } \\
\text { feedback. } \\
\text { Use of mediating artefacts. }\end{array}$ & $\begin{array}{l}\text { Being supervised. } \\
\text { Being coached. } \\
\text { Being mentored. } \\
\text { Shadowing. } \\
\text { Visiting other sites. } \\
\text { Conferences. } \\
\text { Short courses. } \\
\text { Working for a } \\
\text { qualification. } \\
\text { Independent study. }\end{array}$ \\
\hline
\end{tabular}




\title{
Placement replacement: A conceptual framework for designing simulated clinical placement in occupational therapy
}

\author{
Author details \\ ${ }^{1}$ Dr Eli Mang Yee CHU PhD, GCHE, BSc (OT) \\ Formerly, Lecturer, School of Allied Health \\ Australian Catholic University \\ Locked Bag 4115, Fitzroy MDC, Fitzroy Victoria 3065, Australia \\ Associate Professor Loretta SHEPPARD DClinSci, MOT, GCHE, BAppScOT \\ Associate Professor in Occupational Therapy, School of Allied Health \\ Australian Catholic University \\ Locked Bag 4115, Fitzroy MDC, Fitzroy Victoria 3065, Australia \\ Dr Stephen GUINEA PhD, GradDipVocTrainDevelop, BN \\ Coordinator of Health Simulation, Faculty of Health Sciences \\ Australian Catholic University \\ Locked Bag 4115, Fitzroy MDC, Fitzroy Victoria 3065, Australia \\ Professor Christine IMMS BAppSc(OT); MSc(RS), PhD \\ Head of School, School of Allied Health \\ Australian Catholic University \\ Locked Bag 4115, Fitzroy MDC, Fitzroy Victoria 3065, Australia

\section{Correspondence} \\ Dr Stephen GUINEA \\ Faculty of Health Sciences \\ Australian Catholic University \\ Locked Bag 4115, Fitzroy MDC, Fitzroy Victoria 3065, Australia \\ Email: stephen.guinea@acu.edu.au \\ Tel: +61399533857

\section{Author contributions} \\ SCP conceptualisation: E.C., S.G. and L.S. \\ Conceptual framework design: E.C., L.S., S.G. and C.I. \\ Manuscript writing and revisions for important intellectual content: E.C., S.G., L.S. and C.I.
}

\section{Running title}

Placement replacement: The CF-SCP

\footnotetext{
${ }^{1}$ Currently (as of 19 June 2017), Senior Lecturer, Department of Occupational Therapy, School of Primary and Allied Health Care, Monash University, Wellington Road, Clayton Victoria 3800, Australia
} 
Disclosure: The authors declare no financial support or relationships that may pose conflict of interest.

\section{Acknowledgements}

We would like to acknowledge the members of the Occupational Rehabilitation Specialist Interest Group of Occupational Therapy Australia Ltd, (Victoria Division) who participated in the consultation process.

\section{Word count}

5485

This article is protected by copyright. All rights reserved. 


\section{University Library}

\section{- M M N E R VA A gateway to Melbourne's research publications}

Minerva Access is the Institutional Repository of The University of Melbourne

Author/s:

Chu, EMY;Sheppard, L;Guinea, S;Imms, C

Title:

Placement replacement: A conceptual framework for designing simulated clinical placement in occupational therapy

Date:

2019-03-01

Citation:

Chu, E. M. Y., Sheppard, L., Guinea, S. \& Imms, C. (2019). Placement replacement: A conceptual framework for designing simulated clinical placement in occupational therapy. NURSING \& HEALTH SCIENCES, 21 (1), pp.4-13. https://doi.org/10.1111/nhs.12551.

Persistent Link:

http://hdl.handle.net/11343/285125 